\title{
LITERASI PENGGUNAAN MEDIA SOSIAL SEHAT BAGI FORUM ANAK SURAKARTA
}

\author{
Siany Indria Liestyasari ${ }^{1}$, Okta Hadi Nurcahyono ${ }^{2}$, Dwi Astutik ${ }^{3}$, Nurhadi ${ }^{4}$ \\ ${ }^{1234}$ Program Studi Pendidikan Sosiologi Antropologi, Fakultas Keguruan dan Ilmu Pendidikan, \\ Universitas Sebelas Maret \\ Corresponding email: okta.hadi@staff.uns.ac.id
}

\begin{abstract}
ABSTRAK
Gencarnya serangan media sosial dalam kehidupan manusia dewasa ini yang saat ini sungguh tidak bisa dielakkan. Berbagai persoalan dan masalah timbul seiring dengan penggunaan media sosial di masyarakat. Banyak pro dan kontra terkait dengan munculnya berbagai dampak digunakannya media sosial. Kasus-kasus pornografi, penculikan, bahkan terorisme, bullying dan body shaming di media sosial turut ditengarai karena tidak bijaknya para pengguna media sosial, khususnya para remaja. Artikel ini merupakan hasil dari program pengabdian masyarakat yang dilakukan oleh Riset Group Habitus dengan Forum Anak Surakarta. Pengabdian ini bertujuan untuk memeberikan pemahaman atau literasi kepada remaja dan anak terkait penggunaan media sosial sehat. Remaja sebagai pengguna media sosial yang paling aktif oleh karenanya perlu dibekali dengan berbagai pemahaman yang positif terkait bagaimana penggunaan media sosial yang sehat. Metode yang digunakan adalah dengan memberikan penyuluhan berupa ceramah dan diskusi. Hasil pengabdian ini menunjukkan bahwa keberadaan media sosial saat ini memang sudah menjadi kesatuan bagi anak khususnya dalam Forum Anak Kota Surakarta. Dalam kegiatan yang sudah dilakukan diperoleh hasil bahwasannya anak dalam kesehariannya banyak menggunakan waktunya untuk menggunakan media sosial. Keseharian anak sudah dibelenggu oleh keberadaan media sosial itu sendiri.
\end{abstract}

Kata Kunci : Literasi, Penyuluhan, Forum Anak, dan Media sosial.

DOI: https://dx.doi.org/10.20961/dedikasi.v2i2.37834

\section{PENDAHULUAN}

Menurut Wahyudi (2018), salah satu indikator modernitas suatu masyarakat adalah terintegrasinya seluruh tata kehidupan dengan segala bentuk teknologi. Artinya teknologi menjadi hal yang urgent, tak terelakkan dalam kehidupan masyarakat sehari- hari. Teknologi modern juga mampu mengurangi hambatan berinteraksi dalam kehidupan masyarakat (Ariyani \& Nurcahyono, 2014). Menurut penelitian yang dilakukan We Are Social (2018), perusahaan media asal Inggris yang bekerja sama dengan Hootsuite, rata-rata orang Indonesia menghabiskan tiga 
jam 23 menit sehari untuk mengakses media sosial. Dari laporan berjudul "Essential Insights Into Internet, Social Media, Mobile, and E-Commerce Use Around The World" yang diterbitkan tanggal 30 Januari 2018, dari total populasi Indonesia sebanyak 265,4 juta jiwa, pengguna aktif media sosialnya mencapai 130 juta dengan penetrasi 49 persen.

Kemudahan masyarakat dalam mengakses dan kemudahan dalam kepemilikan gawai, menjadi faktor yang paling signifikan dalam memilih media social sebagai sarana beraktifitas dan memilih informasi. Laporan yang ditunjukkan oleh We Are Social (2018) yang bekerja sama dengan Hootsuite yang diterbitkan pada tanggal 30 Januari 2018 mengatakan bahwa 120 juta orang Indonesia menggunakan perangkat mobile, seperti smartphone atau tablet untuk mengakses media sosial, dengan penetrasi 45 persen. Dalam sepekan, aktivitas online di media sosial melalui smartphone mencapai 37 persen. Dari data tersebut menunjukkan bahwa 92 persen masyarakat mengakses Facebook via mobile dengan perbandingan persentase berdasar gender sebanyak 44 persen untuk wanita dan 56 persen adalah pengguna pria.

Penggunaan media sosial yang paling banyak di masyarakat pada kenyataannya banyak didominasi oleh anak remaja hingga dewasa. Pengguna Facebook didominasi golongan usia 18-24 tahun dengan presentase 20,4 persennya adalah wanita dan 24,2 persennya adalah pria. Sementara total pengguna aktif Instagram bulanan di Indonesia mencapai 53 juta dengan presentase 49 persen wanita dan 51 persen adalah pria (We Are Social, 2018). Dari banyaknya data ini tidak mengherankan jika anak dalam generasi millenial ini sedikit banyak menghabiskan waktu mereka untuk bermedia social dibandingkan dengan sudah dilakukan.

Tidak dipungkiri bahwa keberadaan teknologi baru (modern), khususnya sosial media juga mengakibatkan efek negatif dalam beberapa aspek lainnya (Ariyani \& Nurcahyono, 2014). Dampak negatif yang ditimbulkan misalnya: kurangnya interaksi secara langsung (ansos), kasus kriminalitas, pornografi, berita bohong (HOAXS) dan masih banyak yang lainya. Kejahatan di dunia maya atau di melalui media sosial ini terjadi pada orang tua terlebih pada anak. Data KPAI (Siyamitri, 2015)menyebutkan bahwa sejak tahun 2011 hingga tahun 2014 jumlah anak korban pornografi dan kejahatan online di Indonesia mencapai 1.022 anak.

Literasi media merupakan sebuah konsep baru di Indonesia akan tetapi kajian di negara-negara lain di dunia sudah banyak dilakukan (Fitryarini, 2017; Scheibe \& Rogow, 2014; Siyamitri, 2015). Literasi media, pada intinya dapat dipahami sebagai kemampuan untuk secara kritis menganalisis pesan-pesan mediadapat digunakan sebagai cara untuk pemberdayaan individu untuk mampu mengidentifikasi dan mencegah penyebaran hoaks, serta dewasa dalam menggunkan media sosial (Detta Rahmawan, S. Kunto Adi Wibowo, 2012; Scheibe \& Rogow, 2014). Literasi media adalah salah satu upaya yang penting dilakukan dalam rangka meningkatkan pemahaman para remaja dan anak-anak dalam 
menggunakan media online atau media sosial secara bijak. Maka pelatihan literasi media sosial sehat menjadi satu jalan keluar dalam menghadapi berbagai persoalan yang sudah diuraikan sebelumnya.

\section{METODE}

Kegiatan Pengabdian kepada Masyarakat yang dilakukan oleh Riset Group Habitus dari Fakultas Keguruan dan Ilmu Pendidikan, Universitas Sebelas Maret Surakarta. Kegiatan pengabdian kepada masyarakat (PKM) ini merupakan salah satu upaya yang bisa dilakukan untuk meningkatkan pengetahuan dan kemampuan masyarakat khususnya anak dan remaja tentang literasi media sosial sehat. Kegiatan Pelatihan atau penyuluhan merupakan satu bentuk implementasi Tri Dharma Perguruan Tinggi. Dalam pelaksanaannya, kegiatan Pelatihan Literasi Media Sosial Sehat terkait Penanggulangan Hoaks dan permasalahan media sosial yang diselenggarakan bagi anggota Forum Anak Surakarta ini dilakukan dengan menggunakan metode sebagai berikut: Pemaparan materi oleh pemateri, dengan bantuan media menggunakan power point dan video singkat: Pemaparan materi dilakukan dalam rangka memeberikan wawasan kapada peserta mengenai literasi media sosial sehat. Kemudian, dilakukan praktik checking data atau konten berita, apakah berita itu benar atau hoaks. Tahap ini dilakukan dengan berbagai fasilitas yang atau link yang sudah ada. Setelah itu, dilakukan proses diskusi yang bersifat interaktif. Diskusi yang interaktif ini memfasilitasi peserta untuk mengemukakan pertanyaan-pertanyaan terkait dengan literasi media.

\section{HASIL DAN PEMBAHASAN}

Kegiatan Pengabdian Masyarakat (PKM) dengan judul literasi penggunaan media sosial sehat bagi forum anak di Kota Surakarta memiliki sasaran anak-anak yang berada dalam lingkup forum anak di Kota Surakarta. Forum Anak Surakarta sendiri berada di bawah naungan Dinas Pemberdayaan Perempuan, Perlindungan Anak dan Pengabdian pada Mayarakat atau yang biasa dikenal dengan PPPAPM Kota Surakarta. Forum Anak Surakarta menjadi sasaran dalam kegiatan pengabdian ini dengan berlatarbelakang pada keberagaman usia dan pendidikan anak anak yang berada di Forum Anak Surakarta. Selain itu, Forum Anak Surakarta memiliki kegiatan rutin setiap bulannya dalam memberikan pengetahuan baik terkait dengan pendidikan ataupun hal lain terkait dengan perkembangan anak di Kota Surakarta.

Forum Anak Surakarta dipilih sebagai subyek pengabdian karena mengingat pentingnya literasi media sosial bagi anak. Ketua Komisi Perlindungan Anak Indonesia (KPAI) Susanto mengingatkan pentingnya literasi media sosial bagi anak, Apalagi, anak-anak di era digital saat ini sulit dipisahkan dari media sosial (Jurnaliston, 2018). Dengan adanya pelatihan ini diharapkan para anggota forum anak menjadi agen sosial dalam mengakampanyekan media sosial sehat bagi anak kepada teman sebanyanya. 


\section{Kegiatan Awal PKM}

Kegiatan awal pengabdian dilakukan dengan memberikan dan mengadakan kegiatan sosialisasi bagi Forum Anak Surakarta terkait dengan bagaimana menggunakan media sosial yang sehat bagi anak. Hal ini dilakukan mengingat era sekarang, anak-anak sudah tidak asing lagi dengan yang namanya media sosial. Media sosial yang mungkin dulu hanya banyak dimiliki dan digunakan oleh kalangan dan usia tertentu, di era sekarang nampaknya fenomena ini sudah banyak hal yang berubah.

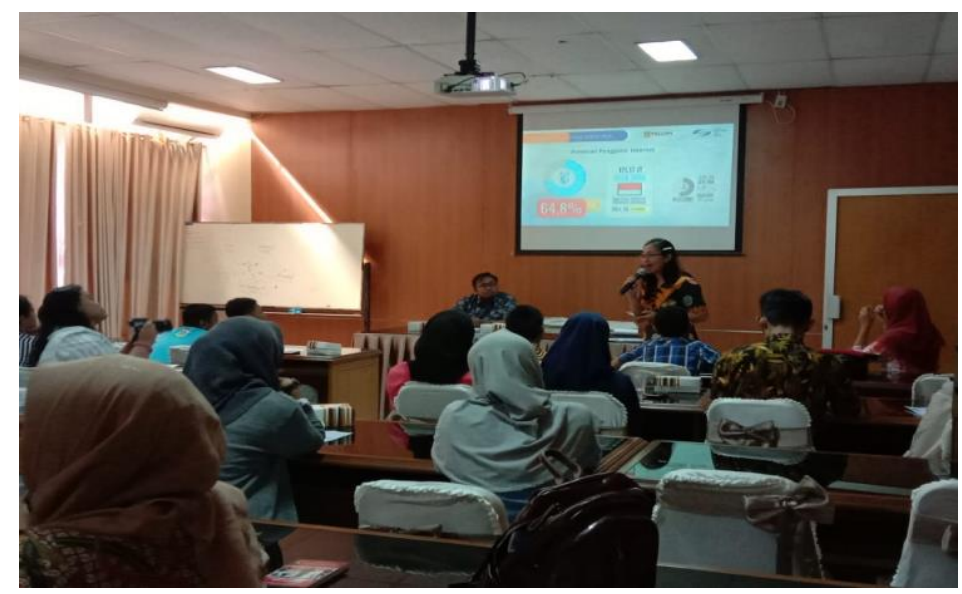

Gambar 1. Fasilitator menyampaikan materi

Pemanfaatan media sosial oleh anak pada saat ini sangat tinggi. Media sosial yang banyak terfasilitasi dengan keberadaan handphone dan kebutuhan mau tidak mau, suka tidak suka, mendorong anak untuk mengkonsumsi media sosial setiap harinya secara bebas. Anak-anak yang mungkin dulu hanya menghabiskan waktu mereka untuk bermain, saat ini mereka lebih banyak memegang gadget dan menggunakan handphone mereka dibandingkan dengan bermain hal lain selain gadget. Pemberian pendidikan bagi anak yang sering menggunakan gadget, perlu diberikan kepada anak-anak agar mereka melek dalam menggunakan gadget mereka. Kegiatan yang sudah dilakukan dalam pengabdian kali ini adalah memberikan sosialisasi bagaimana media sosial sehat bagi pelajar di Forum Anak Surakarta dan Group Riset Habitus Pendidikan Sosiologi Antropologi FKIP, Universitas Sebelas Maret bekerjasama dengan Dinas emberdayaan Perempuan, Perlindungan Anak dan Pengabdian pada Mayarakat (PPPAPM) Kota Surakarta.

\section{Pelaksanaan PKM}

Kegiatan dilaksanakan pada tanggal 07 September bertempat di Aula Gedung Tawangpraja Kompleks Balikota Kota Surakarta. Peserta berjumlah 25 orang dari anggota Forum Anak Surakarta yang notabanenya adalah perwakilan dari kecamatan. Materi utama dari pelaksanaan PKM adalah penggunaan media sosial sehat bagi anak. Tim pengabdi memberikan materi terkait bagaimana cara yang dapat dilakukan dalam menangkal keberadaan hoax disekitar kita. Dari hasil 
kegiatan pengabdian yang dilakukan, tim pengabdi memberikan beberapa hasil terkait dengan kegiatan pengabdian ini, salah satunya adalah beberapa hal yang menyebabkan hoax. Apa yang harus dilakukan saat menerima informasi untuk terhindari dari berita bohong atau hoax. Berikut ini (gambar 2) merupakan salah satu materi yang disampaikan pada pelaksanaan PKM.

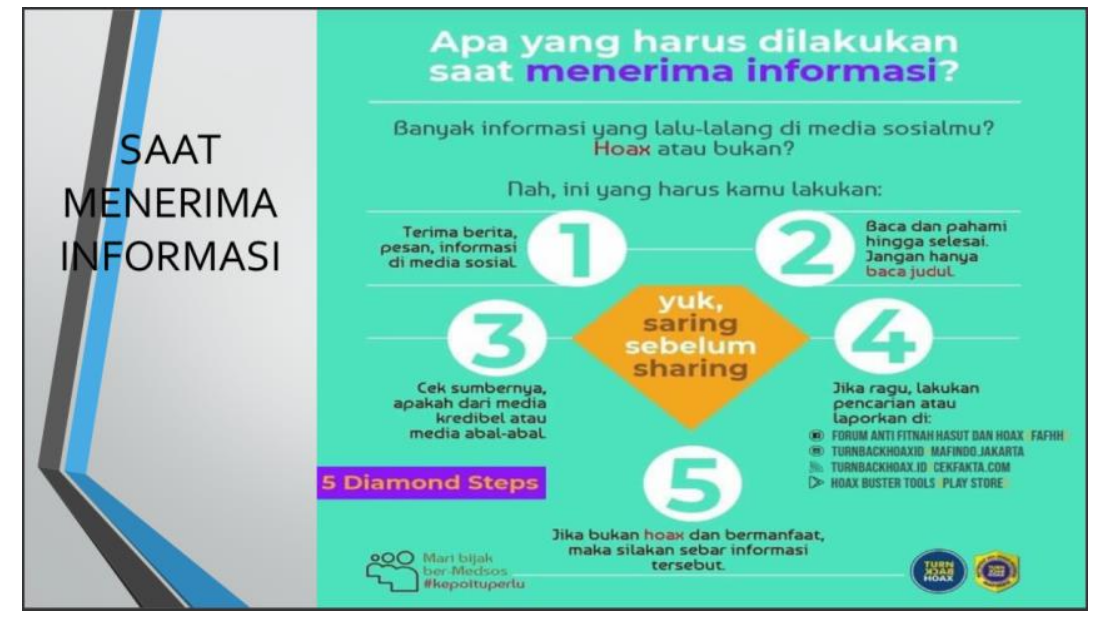

Gambar 2. Materi mengenai “Apa yang harus dilakukan saat menerima informasi?"

Para peserta diajak untuk berpikir mengapa terjadi hoax atau berita bohong. Dari hasil diskusi diperoleh jawaban antara lain:

1. Hanya membaca judul, lalu kemudian menyebarluaskan.

2. Dorongan ingin menjadi pertama yang membagikan

3. Ingin menyelamatkan orang lain

4. Emosional

Ketika sudah terlanjur membagikan atau menyebarluaskan hox atau berita bohong tadi, kita tidak kemudian menghapuskannya. Jika kita menghapuskan langsung tidak menutup kemungkinan berita bohong akan menjadi bermasalah dan kita dapat terduga sebagai orang yang menyebarluaskanya. Tidak menutup kemngkinan kita dapat disangka dalam tindakan kriminalitas. Maka yang seharusnya adalah jika kita mengetahui bahwa berita yang kita sebarluaskan adalah salah, kita berkewajiban untuk mengkonfirmasi atau melakukan klarifikasi bahwa berita yang kita sebarkan tidaklah benar.

Untuk mengetahui kebenaran sebuah berita maka dalam kegitan ini fasilitator memberikan caranya. Salah satunya adalah dengan menggunakan aplikasi "Hoax Buster Tools" seperti gambar berikut ini: 


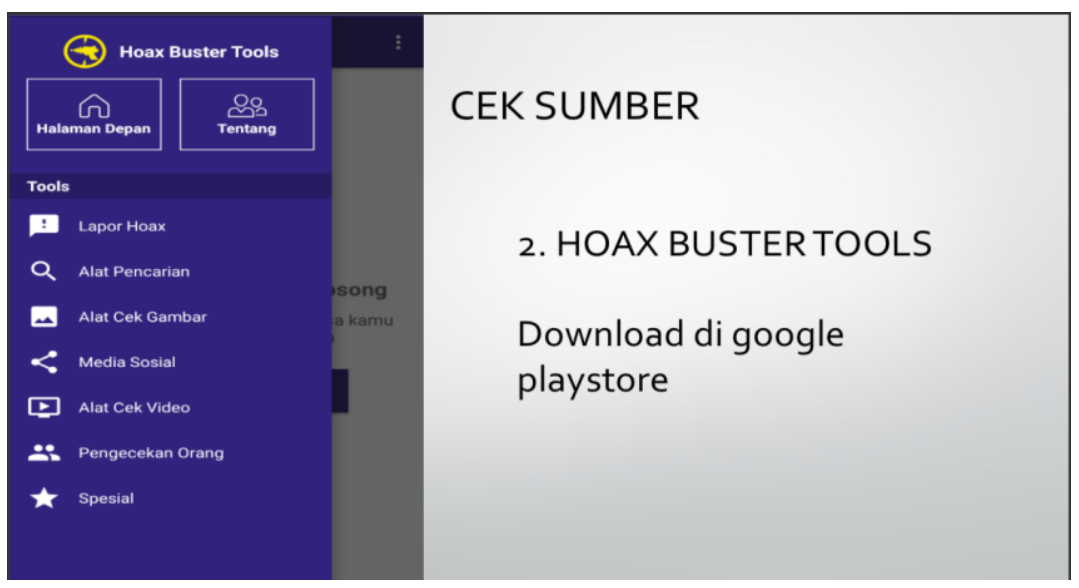

Gambar 3. Materi mengenai "Cek Sumber kebenaran informasi”

Setelah dilakukan proses penyampaian materi mengenai bagaimana cara melakukan proses cek kebenaran sebuah berita, peserta diajak berdiskusi dan memberikan pertanyaan. Kemudian terjadilah proses yang interaktif antara fasilitator dengan peserta seperti gambar berikut ini:

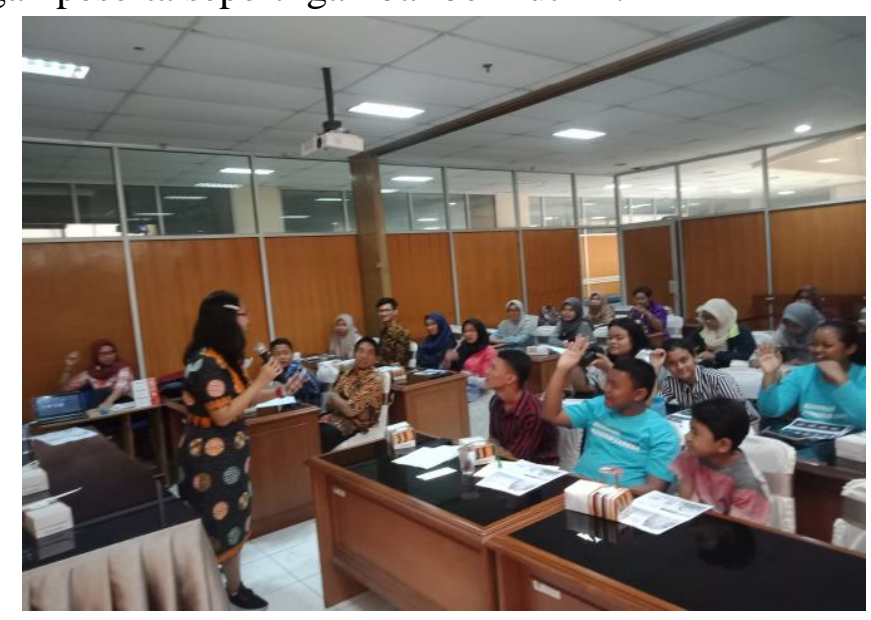

Gambar 4. Interaksi antara fasilitator dan peserta

Dalam kegiatan pengabdian ini, yang menjadi penekanan adalah bagaimana agar anak-anak mampu menggunakan media sosial secara bijak dan juga sehat. Halhal yang bisa dilakukan dalam menerima informasi di media sosial adalah sebagai berikut agar anak termasuk orang dewasa tidak termakan oleh hoax adalah sebagai berikut:

1. Ketika sudah menerima berita ataupun informasi dari media sosial, baca dan pahami hingga selesai, dan jangan hanya membaca judul dari pemberitaan tersebut

2. Cek sumbernya, apakah dari media yang kredibel/dapat dipercaya atau bersumber dari media yang abal-abal dan tidak jelas sumbernya 
3. Jika ragu, lakukan pencarian atau laporkan pada forum anti fitnah, hasut dan hoax (FAFHH), Turnbackhoaxid, dan aplikasi penyaring berita hoax seperti Hoax Buster yang dapat kita unduh melalui aplikasi Play Store di gadget kita. Beberapa strategi yang sudah disebutkan, setidaknya mampu memberikan pengetahuan kepada kita bahwa ketika menerima sebuah informasi, maka sebaiknya yang kita lakukan adalah mengecek kebenaran dari pemberitaan tersebut dengan langkah-langkah sederhana di atas.

\section{KESIMPULAN}

Kesimpulan dari kegiatan pengabdian yang sudah dilakukan adalah, bahwasannya penggunaan gadget di kalangan anak-anak muda dan remaja sudah tidak bisa kita hindarkan lagi. Hal-hal yang bisa kita lakukan untuk mengantisipasi agar anak mampu menggunakan gadget secara bijak adalah dengan melakukan beberapa cara sederhana misalnya mengecek kebenaran sebuah berita dan informasi yang kita terima. Dengan pemberian pengetahuan terkait dengan hal ini, harapannya anak-anak di Forum Anak Surakarta akan memahami bagimana cara menerima berita dan akan memberikan pengetahuan literasi sehat ini bagi temanteman mereka di sekolah. Banyak cara mengetahui kebenaran sebuah berita salah satunya dengan aplikasi "Hoax Buster Tools", selain itu juga melalui gerakan sosial yang disebut MAFINDO (Masyarakat Anti Fitnah Indonesia) dan sebagainya. Dengan melek literasi media sosial sehat, harapannya anak-anak tidak akan secara mudah untuk terjerumus dalam pemberitaan di media sosial yang tidak benar.

\section{DAFTAR PUSTAKA}

Adriana Grahani Firdausy. 2019. Makalah disampaikan dalam Kegiatan Sosialisasi Penggunaan Media Sosial Sehat Bagi Forum Anak di Kota Surakarta.

Ariyani, N. I., \& Nurcahyono, O. (2014). Digitalisasi Pasar Tradisional: Perspektif Teori Perubahan Sosial. Jurnal Analisa Sosiologi, 3(1), 1-12.

Detta Rahmawan, S. Kunto Adi Wibowo, E. M. (2012). Pelatihan Literasi Media Sosial Terkait Penanggulangan Hoaks Bagi Siswa Sma Di Kabupaten Bandung Barat. Jurnal Pengabdian Kepada Masyarakat, 2(12).

Fitryarini, I. (2017). Literasi Media Pada Mahasiswa Prodi Ilmu Komunikasi Universitas Mulawarman I Fitryarini Jurnal Komunikasi 8 (1), 51-67. 8(November), 51-67.

Scheibe, C., \& Rogow, F. (2014). What Is Media Literacy? The Teacher's Guide to Media Literacy: Critical Thinking in a Multimedia World, 19-34. https://doi.org/10.4135/9781483387581.n3 
Siyamitri, P. (2015). Literasi Media Internet pada Kalangan Guru Sekolah Menengah Kejuruan di Kota Medan. Jurnal Simbolika/Volume 1/Nomor 2/September 2015, 1(September), 161-176.

Wahyu Kusumananda Putri. 2018. Riset Ungkap Pola Pemakaian Medsos Orang Indonesia. Kompas.com, diaksesdari https://tekno.kompas.com/read/2018/03/01/10340027/riset-ungkap-polapemakaian-medsos-orang-indonesia.

We Are Social. (2018). Digital in 2018 in Southeast Asia. Diambil dari https://www.slideshare.net/ wearesocial/digital-in-2018-in-southeast-asiapart-2-southeast-86866464 